\title{
OBSERVATIONS ON RECYCLING TECHNIQUES FOR TEXTILES - A REVIEW
}

\author{
S. AISHWARIYA \\ INSPIRE Fellow (DST-GOI) and Assistant Professor, Department of Textiles and Clothing, \\ Avinashilingam University for Women, Coimbatore, Tamilnadu, India
}

ABSTRACT
This paper is a collective review on the different methods available to recycle textile wastes namely composting,
paper making, techniques adopted by fashion brands to recycle old clothing. Special focus is given to technical textiles,
composites and non-woven sectors that involve product development using up cycled wastes. This can be an eye-opener to
researchers and industrialist's worldwide to indulge in more research activities and serve in reducing the landfill
pollution.
KEYWORDS: Textile Waste Management, Up cycling, Down cycling, Technical Textiles, Waste Management \& Textile
Waste Recycling

Received: May 23, 2018; Accepted: Jun 13, 2018; Published: Jul 09, 2018; Paper Id.: IJTFTAUG20184

\section{INTRODUCTION}

Every year a minimum of hundred new textile products evolve with sustainability as a focal point. In an era of increased purchasing power among consumers, more textiles are dumped after their lifecycle, this alarming pollution of the landfill is reminded to be escalating every year. This deposit in a landfill can cause the serious effect to the humans and ecology. On disposing of the materials try to decompose and some be successful and others end as a harmful deposit without being degraded. Decomposing of such materials release toxic greenhouse gases and are also polluting the water bodies directly and indirectly. Scientists are finding prospective in the moon and other planets after tapping of the majority of earth resources. Now, land space is reduced and valued than ever before. In this scenario, it is important for the textile industry to shift to better waste management practices. It will impossible for waste impossible for dumping on landfills.

\section{Escalated Textile Production}

Every textile material has an end after which it will be discarded. When the fiber is $100 \%$ natural it might decompose in few years, but multiplied population in the last decade has made the scientists to find new sources. The growing population demands more clothing which is estimated to be 99 million tonnes per annum which cannot be met completely by natural fibers. [3] The rising needs of people from a fabric is high, that blends and mixtures of textiles are unavoidable. The blends are mostly petrochemical derived synthetics, which is harmful once disposed of in the ecosystem. To sum up: fiber are of two types: namely naturally derived and synthetic origin. Textile materials made from natural fibers are bio-degradable whereas synthetics pose a threat of not being compostable. [4]

\section{Shift towards Sustainability}

Every segment of the textile industry from fiber cultivation/ production to shipping and life cycle assessment is focused on sustainability. In case of quality certification or ISO, the complete product life cycle is 
assessed and then certified. Once the fabric is found not wearable, it is either thrown away or discarded in landfills. Some countries have agencies that collect the old textiles and supply them to orphanage and third world countries. Goodwill is one such charity house that works making one person's waste to another man's wealth. [5-7]

\section{Recycling Textiles Wastes into Clothing}

Increasing awareness among consumers has been once driving force for making greener products. The advertisement and marketing strategy has also shifted to eco-friendliness. [8] Recycled products not down by the consumers. A recent study has identified positive mindset in purchasing recycled textile materials that are eco-friendly and safe for skin. The study also unveils this is seen more in men, rather than women. It could be because men look more into content and women incline towards fashion [9]. International fashion brands have now moved into the use of recycled fibers in their products.

\section{Apparel Lines}

Eco-spun (Welspun Inc) is the brand that sells recycled fabrics made from recycled plastic bottles. Every year 9 million plastic-based wastes are disposed in the landfill and such a significant work in recycling those wastes can be an incredible option for recycled textiles category. Two hundred PET bottles can cover up a normal sized sofa. [10] Eco-fi manufactures textiles made from $100 \%$ recycled PET fibers and is used in a variety of applications like home textiles, car interiors, furnishings, upholstery and craft items. The blends with wool are also very popular in the market. Lutradur ECO, is another sustainable brand that uses disposed of drinking PET bottles and manufactures yarns. One square meter of fabric is made from one two liter PET bottle. Seaqual fiber is made by up cycling wastes from the ocean. This special initiative in 2017 , converts the plastics into a textile fiber.

Safeleigh was launched by leigh fibers recently that uses the cut scarp of protective clothing like firemen garment, bulletproof vest and mix with aramid (natural FR fiber) to create a clothing line that has flame retardancy as a natural character. [11]. Fibers made from organic sources are also suitable to stay in the chain or eco-friendly textile production. The rubbers used in shoe sole, automobile, industry and sports along with the worn-out tyres are all collected and subjected into recycled rubber called Green rubber [12]. The idea being the brainchild of Datuk Vinod Sekhar is now extending its application areas. Rubber from the dandelion's root are some of the newly derived fibers that help in reducing the carbon footprint in textile.

K-sorb (Eco-sorb international) manufactures regenerated textiles which are used in industries, sludge stabilization, and various environmental remediation programme. Barnhardt a very old recycling company that supplies regenerated, reclaim and recycled cotton as homogenous blends with absorbency rate less than virgin cotton. Stein fibers are made by importing textile wastes around the globe, melting and make needle punched non-wovens. This is one of the very popular brands that caters to various field of technical textiles like filtration, insulation, automobile, packaging and invisible textiles.

\section{Brands with Sustainability}

Patagonia has developed methods to recycle old PET bottles. These recycled fibers are available in clothing lines of Armani Jeans, Eco-simple, Marks \& Spencer. There are few more companies that are launching their labels using PET bottle recycling. Levi Strauss uses eight plastic bottles to make one pair of Denim pant. 
Nike has taken initiatives to reduce the size of the show box, monitoring the effluent discharged, recycle the cloth hangers, collect the extra clothing from the public, recycle and use the yarns for make new apparels and footwear. In collaboration with NASA, they have designed various steps for clean production. Nike has designed the Team India Kit for World Cup 2015 for the Indian Cricket team using 15 bottles for the jersey and 18 bottles for the pants. This sustainability award winner has collaborated with Ocean conservation group to recycle the waste fishing nets and plastics from the ocean into fiber for clothing. Parley has collected the ocean waste and made a swimwear for their customers. H\&M is one of the leading stores, that uses recycled PET bottles and develop fashionable clothing. BIONIC is one such made from recycled ocean waste. Repreve is another brand that markets yarns from PET bottles and reports convey that 27 bottles are used in making one graduate gown. Four million plastic bottles are testified to be recycled by this company.

\section{TEXTILE WASTE RECYCLING OPTIONS}

\section{Composting}

In the recent times, awareness on the ill effects of non-degradable synthetics has opened huge opportunities for manufacturers to think of degradable/ compostable textiles. Nappy pads, wipes, mulching sheets for agro-textiles, interiors for cars are now made in a way that it will be back to nature after its life cycle.

This is the era of non-wovens and disposals. It will be lucrative if researches in the industry can focus on materials with $100 \%$ natural origin that can be completely degraded when thrown on to the landfills after their life cycle. Natural and regenerated fibers can be processed in this way. Biodegradable plastics from PLA are hitting the market. PLA (Poly lactic acid) derived from Corn. The natural anti-microbial property is further enhanced and applied in medical textiles. This fabric is compostable/degradable when thrown in the landfill. [13-15]

Various researches are being done to use the post-industrial waste, that is lack of chemicals into acompost and applying to the plants as bio-manure. Fortification and enrichment are possible using effective microorganisms to make the medium more nourishable to the soil, plant, and waterbodies. [16]

It is seen that natural fibers when cut into smaller particles and then disposed of tend to degrade easily. The technique is much appreciated especially in interior designing and automobile sector where the use of natural fibers can also reduce the weight of the automobile and ensuring better mileage. The package textiles that are mainly focusing on research and business opportunities with eco-friendly textile materials are now into making bags that are compostable. Natural fibers with least size possible and made into non-wovens can be a very effective material to be used in making carry bags, that can be a replacement of wastes. [17-19] The harmful textile effluents are also given treatment with microbes and further made into a compose to ensure safe disposal. [20,21]

\section{Regeneration}

Reclaimed recycled fibers can be used to make wiping cloth, yarns - untwisted and re-spun into new yarn variety, mattress and wadding. Regeneration is another technique in which the fiber is regenerated from a natural source by heat and chemicals. For examples, Tencel, Lyocell, Seacell are some of the popular brands that made textile fibers from wood. The trees are cut and the wood will be chopped to small particles, which when treated with chemicals and under high temperature and pressure will be passed through a spinneret and made into a filament for textiles. These are used to make fabrics with sustainable properties. [22] 


\section{Non-Woven Technology}

The textile production technique that uses very short fibers and bonding them with heat, resin, chemical, and ironing; creating a textile-like material is called non-woven. The recycled fibers may be heterogeneous and hence a systematic fiber length and fabric formation is not possible, and non-woven can be resourceful. In this technology, composites, which uses fiber and polymer matrix bonded under heat and pressure, to form a compressed medium that can be very much suitable for agro, build, geo, acoustics and filtration textiles.

Composite technology is also advancing with the FRP (fiber reinforced polymers) that find their origin from recycled materials. Most of the thermoplastic fibres like polyester, polyamide will be melted and converted intogranules for recycled fibre production. Natural fibres are also used in making composites. Pineapple fibers is used as reinforcement purpose. Coir, Basalt, kenaf, hemp, bamboo, flax, jute, sisal, areca nut and banana are some of the popular nonconventional fiber types hitting the market. These can also be used in non-woven production to melt and hold the base matrix of textile material. Such recycled materials have good potential to be used in insulation. [23-25]

\section{Technical Textiles}

In the olden days, textiles were made and then tested for their suitability for an end user and if positive will be made into the required product for a purpose. Contrastingly, based on the properties required in the end product the fiber selection, yarn properties to functional finishing is decided and executed. Technitex or technical textiles is now framed as a huge banyan tree with all the application areas being connected in the main bark. Recycled textiles are used in filtration purposes [26] Recycled fibers are also used in automobile interiors, agro-textiles, reinforcement in geotextiles, acoustics, textiles for building construction purpose, upholstery, package textiles and food packing materials.

\section{Paper Making Alternatives}

Discussing on the possibilities of recycling old textiles, it is interesting to know, that the old textiles are used in making papers. This is a conventional way of making high-quality paper. It is believed that the American currency and bond papers [27]. Eco-friendly paper making industry is upcoming that finds old fabrics are an excellent binding material. Bio-mass, agro waste and old cotton textiles serve in building the matrix in the handmade paper. [28] This is extremely beneficial as it reduces the stress on deforestation. Carbon emissions due to deforestation is as high as $25 \%$. Such recycled fibers used in making paper are further made into the tea bag, carry bag, envelope, book papers. In contrast to the word upcycling, the products that are made with less value than conventional is called downcycling. [29] It uses less energy than conventional paper production. There is no use of chlorine that is harmful as an effluent. The quality of the paper is also much better up to $70 \%$ that the other category papers that sum up to 35\%. [30] By application of recycling technology, we can minimize the use of dye since the fabrics recycled are already dyed. There is a huge bulk of textiles from a postconsumer section which has been less explored but has a huge potential for recycling and application in different forms of technical textiles

\section{CONCLUSIONS}

A recent report published by the US government unveils that fifty on eighty garments are found to have NPE (Nonylphenol Ethoxylates), which is a harmful chemical that can be possibly released during washing, resulting in creating a toxin when mixed with water bodies. It is one among the many compounds commonly found in textile materials and proved to be dangerous. pollution and harmful effects of textiles are ever increasing. [31-33] It is critical to focus on waste 
management in textiles much equal to inventing new products and technologies. Sustainability is the key to run a business in the modern era, especially if the company is into exporting. Discarded waste fabrics are now seen as a new resource and a wealth potential.

\section{REFERENCES}

1. Bertram, R. F., \& Chi, T. (2016). A Study of Companies' Business Responses to Apparel E-commerce's Environmental Impact.

2. Huang, J., Zhao, R., Huang, T., Wang, X., \& Tseng, M. L. (2018). Sustainable Municipal Solid Waste Disposal in the Belt and Road Initiative: A Preliminary Proposal for Chengdu City. Sustainability, 10(4), 1147.

3. Mukherjee, A. (2017). Clothes from Plastic Bottles!

4. Khalili, P., Tshai, K. Y., \& Kong, I. (2017). Natural fiber reinforced expandable graphite filled composites: Evaluation of the flame retardancy, thermal and mechanical performances. Composites Part A: Applied Science and Manufacturing, 100, 194205.

5. Koch, K., \& Domina, T. (1999). Consumer textile recycling as a means of solid waste reduction. Family and Consumer Sciences Research Journal, 28(1), 3-17.

6. Hawley, J. M. (2006). Textile recycling: A systems perspective. In Recycling in textiles. Woodhead Publishing Limited, UK.

7. WANG, X. L. (2017). The Study of Classifying Recycling of City Waste Textile and Garment. DEStech Transactions on Engineering and Technology Research, (oect).

8. Charter, M., \& Polonsky, M. J. (Eds.). (2017). Greener marketing: a global perspective on greening marketing practice. Routledge.

9. Raut, P. B., Moore, M. M., Rothenberg, L., Devine, G., \& Leonas, K. (2016). Green Apparel Consumption: An Empirical Examination of Behaviour versus Attitudes.

10. Charter, M., \& Polonsky, M. J. (2017). Achieving Sustainability: Five Strategies for Stimulating Out-of-the-Box Thinking Regarding Environmentally Preferable Products and Services. In Greener Marketing (pp. 72-83). Routledge.

11. Hawley, J. M. (2014). Textile Recycling. In Handbook of Recycling (pp. 211-217).

12. http://www.therakyatpost.com/business/2015/03/12/green-rubber-reinvents-the-wheel/

13. Radhakrishnan, S. (2015). Environmental Communication and Green Claims of Textile Products. In Handbook of Sustainable Apparel Production (Vol. 375, No. 398, pp. 375-398). ROUTLEDGE in association with GSE Research.

14. Schneider, J. S. (2016). Design of biobased and biodegradable-compostable engineered plastics based on poly (lactide). Michigan State University.

15. Mejía, M. L., Zapata, J., Cuesta, D. P., Ortiz, I. C., Botero, L. E., Galeano, B. J., \& Hoyos, L. M. (2017). Properties of Antibacterial Nano Textile for Use in Hospital Environments. Revista Ingeniería Biomédica, 11(22), 13-19.

16. Aishwariya, S., \& Amsamani, S. (2012). Evaluating the efficacy of compost evolved from bio-managing cotton textile waste. Journal of Environmental Research And Development Vol, 6(4).

17. Palamutcu, S. (2017). Sustainable Textile Technologies. In Textiles and Clothing Sustainability (pp. 1-22). Springer, Singapore.

18. Keune, S. (2017). Co-designing with plants. Degrading as an overlooked potential for interior aesthetics based on textile structures. The Design Journal, 20(sup1), S4742-S4744. 
19. Dissanayake, G., \& Perera, S. (2016). New Approaches to Sustainable Fibres. In Sustainable Fibres for Fashion Industry (pp. 1-12). Springer, Singapore.

20. Krishnamoorthy, R., Kannadasan, N., \& Renuga, D. (2015). Bioconversion Of Textile Sludge Employing The Earthworm Eisenia Fetida And Its Impact On The Growth Of Cajanus Cajan. Int J Nano Corr Sci and Engg, 2(5), 422-428.

21. Guha, A. K., Rahman, O., Das, S., \& Hossain, M. S. (2015). Characterization and Composting of Textile Sludge. Resources and Environment, 5(2), 53-58.

22. Sülar, V., Oner, E., Devrim, G., Aslan, M., \& Eser, B. (2016). A comparative study on performance properties of yarns and knitted fabrics made of biodegradable and conventional fibers. Fibers and Polymers, 17(12), 2085-2094.

23. Bongarde, U. S., \& Shinde, V. D. (2014). Review on natural fiber reinforcement polymer composites. International Journal of Engineering Science and Innovative Technology, 3(2), 431-436.

24. Leão, A. L., Cherian, B. M., Narine, S., Souza, S. F., Sain, M., \& Thomas, S. (2015). The use of pineapple leaf fibers (PALFs) as reinforcements in composites. In Biofiber Reinforcements in Composite Materials (pp. 211-235).

25. http://www.textilevaluechain.com/index.php/article/technical/item/273-textiles-waste-recycling

26. Zander, N. E., Gillan, M., \& Sweetser, D. (2017). Composite Fibers from Recycled Plastics Using Melt Centrifugal Spinning. Materials, 10(9), 1044.

27. www.paperenvironment.org/recycling.html.

28. https://www.valmet.com/board-and-paper/recycled-fiber/

29. http://www.greenpressinitiative.org/documents/recycledfiberfactsheet-EPN.pdf

30. http://www.glatfelter.com/sustainability/commitment/recycled_fiber.aspx.

31. www.greenpressinitiative.org/documents/recycledfiberfactsheet-EPN.pdf

32. http://topabelding.blogspot.com/2013_01_01_archive.html

33. https://waste-management-world.com/a/trash-talking-textile-recycling 